\title{
Endoscopic Endonasal Surgery for Adult Craniopharyngiomas
}

\author{
Adel R. Al Melesy, ${ }^{1}$ MD.
}

\author{
* Corresponding Author: \\ Adel R. Al Melesy \\ adelalmelesy@gmail.com
}

Received for publication October 26, 2020; Accepted February 22, 2021; Published online February 22, 2021.

\section{Copyright 2021 The Authors published by Al-Azhar University, Faculty of Medicine, Cairo, Egypt. All rights reserved. This an open-access article distributed under the legal terms, where it is permissible to download and share the work provided it is properly cited. The work cannot be changed in any way or used commercially. \\ doi: 10.21608/aimj.2021.45910.1334. \\ ${ }^{1}$ Neurosurgery Department, Faculty of Medicine, Al-Azhar University.}

\begin{abstract}
Background: Craniopharyngiomas are challenging tumors that occur in the sellar or suprasellar regions most frequently. The endoscopic endonasal transsphenoidal approach is a minimal-invasive technique for managing craniopharyngiomas.

Aim of the study: is to evaluate of endoscopic endonasal transsphenoidal approach in management of craniopharyngioma as regard the indications, operative difficulties, post-operative complications and outcomes.

Patients and Methods: An analytical prospective study conducted on 12 Craniopharyngioma patients treated via endoscopic endonasal, transsphenoid approach in Al Azhar university hospitals. Follow up of patients done clinically and radiologically over 6 months.

Results: The study included 12 patients, 2 (16.7\%) males and 10 (83.3\%) females, with mean age of 40 years. In 9 patients (75\%), gross total resection was achieved. The most popular surgical complications in our series were DI (50\%), CSF rhinorrhea (33.3\%) and DCL and seizures (16.7\%) respectively. None of our patients suffered from worsening of endocrinological or visual outcome postoperatively.

Conclusion: The combination of IPACK block with ACB has the potential of being an adequate technique for management of acute postoperative pain after TKA but this needs more researches of larger samples and use of other types of local anesthetics with different volumes and concentrations.
\end{abstract}

Keywords: Craniopharyngioma; Endoscopy; Skull base; Endonasal Approach; Transsphenoidal surgery.

Disclosure: The authors have no financial interest to declare in relation to the content of this article. The Article Processing Charge was paid for by the authors.

Authorship: All authors have a substantial contribution to the article.

\section{INTRODUCTION}

Benign tumors resulting from squamous epithelial remains of Rathke's pouch are craniopharyngiomas. These represent about 2-5\% of all intracranial tumors and about $5.6-13 \%$ in children. The overall 1.3 per million person-year incidence of craniopharyngiomas. A bimodal age distribution with peak occurrence rates in children aged 5-14 years and in adults aged 50-74 years has been reported. In newborns and infants, craniopharyngiomas are uncommon, with just $5 \%$ of patients among birth and 5 years of age. . Adamantinomatous and papillary subtypes were identified on the basis of a histologic finding. Craniopharyngiomas are considered to be benign pathologies, from a histopathological point of view. Local adhesiveness, propensity to produce a mass impact, high rates of surgical failure, and increased risk of repeated surgical mortality / morbidity may result in these possibly aggressive tumors being deemed "malignant" from a surgical and clinical viewpoint. ${ }^{2}$ An endonasal approach could be used to resect intrasellar and infra-diaphragmatic lesions. With the emergence of endoscopic endonasal surgery (EES), suprasellar and select intraventricular tumors that were only accessible by craniotomy can now be resected by endoscopic endonasal surgery, often with better clinical results relative to transcranial resection. $^{3}$

Compared to transcranial methods managed by nasoseptal flaps and multilayer repair, CSF leak is the most pronounced drawback of endoscopic endonasal surgery. ${ }^{4}$ To avoid local recurrence, radiotherapy is also advised for residual or recurrent craniopharyngioma following surgical resection. Radiotherapy, however, is not always successful and can make it harder to remove tumors. ${ }^{5}$

The aim of this study is evaluation of endoscopic endonasal trans-sphenoidal approach in management of craniopharyngioma as regard the indications, 
operative difficulties, post-operative complications and outcomes.

\section{PATIENTS AND METHODS}

An analytical prospective study conducted on 12 Craniopharyngioma patients that were treated via endoscopic endonasal, trans-sphenoidal approach in $\mathrm{Al}$ Azhar university hospitals. Follow up of patients done clinically and radiologically over 6 months.

Inclusion criteria: Sellar, Suprasellar, Infradiaphragmatic, sub-chiasmatic Craniopharyngioma in adult patients (De novo cases). Exclusion criteria: Pediatric below 18 years, Recurrent cases, intraventricular, sub-frontal, posterior fossa craniopharyngiomas and Associated intracranial lesions.

Endoscopic equipment: STORZ Xenon nova 300(20134020) with CONVMED3CCD Digital Camera. STORZ Xenon 300(20133120) with SCD Image 1hub22201020 Digital Camera. The patient put supine and the head placed in a rigid position, extended slightly, and rotated slightly right. The head is raised above the heart to facilitate venos drainage. Turbinates of inferior, middle, and superior are identified. The posterior medial aspect of the middle turbinate was removed by angled scissors, this was done in some cases and in order to further widen the virtual space among the middle turbinate and the nasal septum and establish an appropriate surgical route, the head of the middle turbinate was delicately dislocated laterally. The sphenoid ostium is defined after the middle and superior turbinates are laterally retracted. The sphenoid ostium is enlarged, and broad bilateral sphenoidotomies are carried out, producing a single large cavity in which to operate. In order to have broad access to bilateral medial opticocarotid recesses, the tuberculum sellae bone and the planum sphenoidale reaching the posterior ethmoid were removed laterally, including the lateral tubercular strut. In a midline location and in linear or cruciate fashion, the dura was incised. The pituitary gland can be mobilized laterally or inferiorly to maximize exposure after opening the dura. Resection of the tumor and adhesions to the optic nerve, chiasm, and pituitary stalk are severely dissected, and the separation of the tumor from the hypothalamus is taken with great caution. To prevent damage to the cavernous sinus and neighboring cranial nerves, the discovery of the lateral sella with a blunt ring curette must be followed gently. By electrocautery or injection of hemostatic agents into the sinus, the superior intercavernous sinus was controlled. Lumbar drain was not inserted routinely in our cases. Using a fascia lata graft, accompanied by a vascularized nasoseptal flap, synthetic dural sealant, and absorbable packing, skull base reconstruction was carried out. Patients with pituitary affection were given hydrocortisone $100 \mathrm{mg}$ every 8 hours and tapered on the next five days. A protocol for monitoring fluid balance and detecting diabetes insipidus (DI). If DI diagnosed add Minrin $0.2 \%$ every 6, 8 or 12 hours. Nasal packs were removed on the second day and monitored for nasal or post nasal CSF drainage for at least several hours. Scheduled follow up of visual and hormonal disturbances. MRI brain with contrast after 3 months.

\section{RESULTS}

All patients had a mean age of the mean disease duration was $(4 \pm 1.4)$ months. The majority (83.3\%) of patients were females; while (16.7\%) were males. (8.3\%) of patients had ANS deficit, (25\%) had cognitive dysfunction and (8.3\%) had DCL. (83.3\%) of patients had diminution of vision and bitemporal hemianopia respectively. (75\%) of patients had headache and vomiting, while (16.7\%) had seizures. (25\%) of patients had obesity, (66.7\%) had fatigability, (33.3\%) had amenorrhea, (50\%) had sleep disturbances, while (16.7\%) had polyuria \& polydipsia.

(8.3\%) of patients had high blood sugar, high prolactin and GH respectively, and (33.3\%) had low T3 and T4 and (25\%) had low cortisol levels. The average tumor size was $(4.1 \pm 1.04) \mathrm{cm}^{3}$. $(58.3 \%)$ had lobular shape and (41.7\%) had oval shape. (58.3\%) were cystic and (41.7\%) were mixed. (75\%) of patients had GTR, while (25\%) had STR (Table 1).

\begin{tabular}{|l|l|l|}
\hline \multicolumn{2}{|l|}{ Variables } & Frequency (\%) \\
\hline $\begin{array}{l}\text { Extent of } \\
\text { resection }\end{array}$ & GTR & $9(75 \%)$ \\
STR & $3(25 \%)$ \\
\hline
\end{tabular}

Table 1: Operative data (extent of resection) among 12 craniopharyngioma patients (GTR: Gross Total Resection. STR: Subtotal Resection).

(66.7\%) of patients had complete vision improvement, while (33.3\%) had partial improvement, achieving $66.7 \%$ efficacy of resection operation (Table 2).

(16.7\%) had DCL and seizures, (50\%) had DI, while (33.3\%) had CSF rhinorrhea (Table 2, Fig. 1).

\begin{tabular}{|l|l|l|}
\hline \multicolumn{2}{|l|}{ Variables } & \multicolumn{1}{|c|}{$\begin{array}{c}\text { Frequency } \\
(\%)\end{array}$} \\
\hline $\begin{array}{l}\text { Favorable } \\
\text { outcomes } \\
\text { “Efficacy” }\end{array}$ & Vision improvement & $8(66.7 \%)$ \\
\hline $\begin{array}{l}\text { Un-favorable } \\
\text { outcomes } \\
\text { "Safety” }\end{array}$ & Dartial improvement & $4(33.3 \%)$ \\
\hline
\end{tabular}

Table 2: Outcome data among 12 craniopharyngioma patients (DI: Diabetes Insipidus).

The 12 craniopharyngioma patients were classified according to efficacy outcome "complete visual 
improvement”, into 2 independent groups: Complete visual improvement group (8 patients) and Partial visual improvement group (4 patients). Significant increase in diminution of vision in completely improved group; compared to partially improved group; with significant statistical difference ( $\mathrm{p}=$ 0.035). Significant increase in seizures, amenorrhea, sleep disturbances and polyuria \& polydipsia, in partially improved group; compared to completely improved group; with significant statistical difference $(\mathrm{p}<0.05)$. Non-significant difference as regards all the remaining clinical and neurological data $(\mathrm{p}>0.05)$.

GTR achieved (75\%) success rate of completely improved patients, while STR achieved only (25\%) success rate of completely improved patients (Table 4).

Outcome data :significant increase in post-operative DCL and seizures in partially improved group;

\begin{tabular}{|c|c|c|c|c|}
\hline \multirow{2}{*}{\multicolumn{2}{|c|}{ Variable }} & $\begin{array}{l}\text { Completely } \\
\text { improved } \\
(8) \\
\end{array}$ & $\begin{array}{l}\text { Partially } \\
\text { improved } \\
(4) \\
\end{array}$ & Mann-Whitney's U test \\
\hline & & Median (IQR) & Median (IQR) & P value \\
\hline \multicolumn{2}{|l|}{ Age (years) } & $38.5(27-51)$ & $43(22.5-61)$ & $=0.7331$ \\
\hline \multicolumn{2}{|l|}{ Disease Duration (month) } & $4(3-5)$ & $4.5(3-5.5)$ & $=0.7290$ \\
\hline \multirow{2}{*}{\multicolumn{2}{|c|}{ Variable }} & \multirow{2}{*}{$\begin{array}{l}\text { Completely } \\
\text { improved } \\
\text { (8) }\end{array}$} & \multirow{2}{*}{$\begin{array}{l}\text { Partially } \\
\text { improved } \\
\text { (4) }\end{array}$} & Chi square test \\
\hline & & & & $P$ value \\
\hline Gender & $\begin{array}{l}\text { Female } \\
\text { Male }\end{array}$ & $\begin{array}{l}6(75 \%) \\
2(25 \%) \\
\end{array}$ & $\begin{array}{l}(100 \%) \\
0(0 \%)\end{array}$ & $=0.2943$ \\
\hline $\begin{array}{l}\text { ANS deficit } \\
\text { Cognitive dysfunction } \\
\text { DCL }\end{array}$ & $\begin{array}{l}\text { +ve } \\
+ \text { ve } \\
+ \text { ve }\end{array}$ & $\begin{array}{l}0(0 \%) \\
1(12.5 \%) \\
0(0 \%)\end{array}$ & $\begin{array}{l}1(25 \%) \\
2(50 \%) \\
1(25 \%)\end{array}$ & $\begin{array}{l}=0.1573 \\
=0.1757 \\
=0.1573\end{array}$ \\
\hline $\begin{array}{l}\text { Diminution of vision } \\
\text { Bitemporal hemianopia }\end{array}$ & $\begin{array}{l}\text { +ve } \\
\text { +ve }\end{array}$ & $\begin{array}{l}8(100 \%) \\
7(87.5 \%)\end{array}$ & $\begin{array}{l}2(50 \%) \\
3(75 \%)\end{array}$ & $\begin{array}{l}=0.035^{*} \\
=0.6000\end{array}$ \\
\hline $\begin{array}{l}\text { Headache } \\
\text { Vomiting } \\
\text { Seizures }\end{array}$ & $\begin{array}{l}\text { +ve } \\
+ \text { ve } \\
+ \text { ve }\end{array}$ & $\begin{array}{l}6(75 \%) \\
6(75 \%) \\
0(0 \%) \\
\end{array}$ & $\begin{array}{l}3(75 \%) \\
3(75 \%) \\
2(50 \%)\end{array}$ & $\begin{array}{l}=1.000 \\
=1.000 \\
=0.035^{*}\end{array}$ \\
\hline $\begin{array}{l}\text { Obesity } \\
\text { Fatigability } \\
\text { Amenorrhea } \\
\text { Sleep disturbances } \\
\text { Polyuria \& polydipsia }\end{array}$ & $\begin{array}{l}\text { +ve } \\
+ \text { ve } \\
\text { +ve } \\
\text { +ve } \\
\text { +ve }\end{array}$ & $\begin{array}{l}2(25 \%) \\
4(50 \%) \\
1(12.5 \%) \\
2(25 \%) \\
0(0 \%) \\
\end{array}$ & $\begin{array}{l}1(25 \%) \\
4(100 \%) \\
3(75 \%) \\
4(100 \%) \\
2(50 \%) \\
\end{array}$ & $\begin{array}{l}=1.000 \\
=0.0973 \\
=0.038 * \\
=0.019 * \\
=0.035^{*}\end{array}$ \\
\hline
\end{tabular}

Table 3: Comparison between the 2 groups as regards baseline clinical and neurological data using MannWhitney's U and Chi square tests.

\begin{tabular}{|l|l|l|l|l|}
\hline \multicolumn{2}{|l|}{ Variable } & $\begin{array}{l}\text { Completely improved } \\
(8)\end{array}$ & $\begin{array}{l}\text { Partially improved } \\
(4)\end{array}$ & Chi square test \\
\cline { 3 - 5 } Extent of resection & GTR & $\begin{array}{l}\mathbf{6 ( 7 5 \% )} \\
\mathbf{2 ( 2 5 \% )}\end{array}$ & $\begin{array}{l}3(75 \%) \\
1(25 \%)\end{array}$ & $=1.000$ \\
\hline
\end{tabular}

Table 4: Comparison between the 2 groups as regards extent of resection using Chi square test..

\begin{tabular}{|c|c|c|c|c|}
\hline \multicolumn{2}{|l|}{ Variable } & $\begin{array}{l}\text { Completely improved } \\
\text { (8) }\end{array}$ & $\begin{array}{l}\text { Partially improved } \\
\text { (4) }\end{array}$ & Chi square test \\
\hline $\begin{array}{c}\text { Complications outcomes } \\
\text { "Safety" }\end{array}$ & $\begin{array}{l}\text { DCL \& Seizures } \\
\text { DI } \\
\text { CSF Rhinorrhea }\end{array}$ & $\begin{array}{l}0(0 \%) \\
4(50 \%) \\
2(25 \%)\end{array}$ & $\begin{array}{l}2(50 \%) \\
2(50 \%) \\
2(50 \%)\end{array}$ & $\begin{array}{l}=0.035^{*} \\
=1.000 \\
=0.407\end{array}$ \\
\hline
\end{tabular}

Table 5: Comparison between the 2 groups as regards post-operative complications using Chi square test. 


\section{Case samples}

46 years old female with headache and diminution of vision. visual acuity was 6/12 both eyes, bitemporal hemianopia while fundus examination was normal. No hormonal abnormalities. MRI brain with contrast showed sellar \& suprasellar mass of mixed consistency. Near Total Resection was achieved by transplanum transtuberculum transsellar approach. Post-operative transient DI which completely resolved 3 months after surgery and the visual disturbance improved postoperatively. (Fig. 2a, 2b).
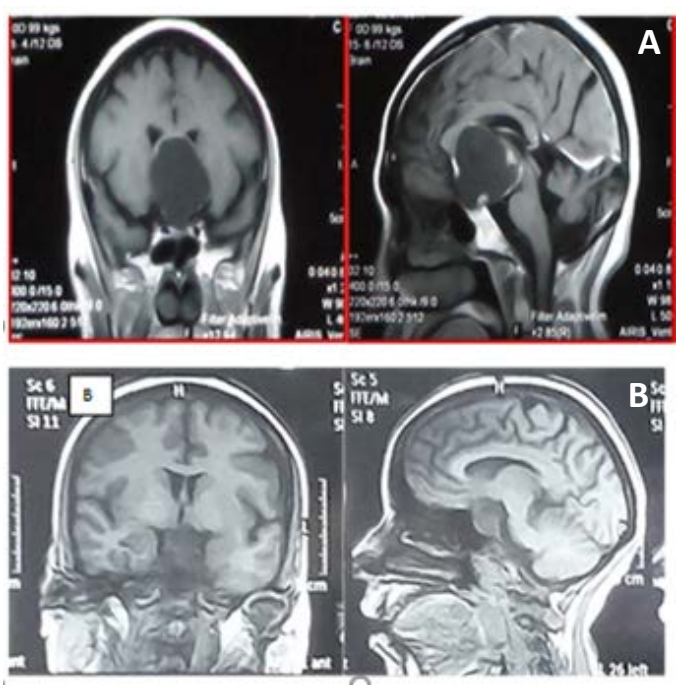

Fig 2: (A) Preoperative Axial, Sagittal and coronal contrast-enhanced T1-weighted MR images of a case of craniopharyngioma with postfixed chiasma. (B) Postoperative Axial, Sagittal and coronal T1weighted MR images of a case of craniopharyngioma with postfixed chiasma.

\section{DISCUSSION}

Owing it to an extremely variable growth pattern, craniopharyngiomas are deemed very difficult lesions to treat. Disputes about surgical management still exist. In recent years, "pure" endoscopic endonasal procedures aimed for the removal of craniopharyngiomas have begun to be carried out by numerous surgical centers around the world, already assured of endoscopic endonasal management of pituitary tumors.

Our study included 12 patients, (mean age 40 years). Patients below 18 years were excluded which were consistent with other big series as (Park et al., 2017) ${ }^{6}$ study which included 111 adult patients (95.6\%) with a mean age of 43.8 years (range 14-74 years) and 5 children (4.4\%) with a mean age of 15.6 year (range 14-17) or (Cavallo et al., 2014) ${ }^{7}$ study which included 83(81.6\%) adult patients with a mean age of 50.36 years (range 18-83 years) and 20 children (19.4\%) with a mean age of 10.1 years. This was attributed to the fact it was our initial experience with this technique. The chief complaint in our study was visual disturbance in 10 cases (83.3\%), endocrinopathy in 4 cases (33.3\%), and headache in 9 cases $(75 \%)$. This is compatible with (Park et al., 2017) results where vision loss was the most common presenting symptom (83\%) followed by headache (48\%) and endocrinopathy (33\%), while as (Cavallo et al., 2014) found that visual disturbances were present in $76.7 \%$ of patients followed by endocrinopathy in $56.6 \%$ of adult patients and hypothalamic symptoms in $24.3 \%$ of adult patients.

Prior to and after surgery, our patients received a comprehensive neuro-ophthalmological examination. Of the 10 patients with preoperative visual deficits $80 \%$ had full resolution of their visual impairment and $20 \%$ had partial resolution enhancement. However, no patient had deteriorating vision after surgery due to damage to the optic apparatus. These findings are consistent with those of (Park et al., 2017), where $76 \%$ of the 89 patients with preoperative visual deficits reported improvement and $49 \%$ reported postoperative normalization of visual deficits. Overall, postoperatively, a slight 7.3 $\%$ suffered visual degradation. On the other hand, (Cavallo et al., 2014) found that of the 103 patients, visual deficit improvement happened in $74.7 \%$ ,deficiency normalization was accomplished in 5.1 $\%$, while $17.7 \%$ stayed the same, $2.5 \%$ had worsening of preoperative visual deficit, whereas in the Pittsburgh group study of the 16 patients, preoperatively, 14 patients had gradual visual defects, 6 (43\%) of which had full resolution of their visual defect and 7 (50 \%) had enhancement but no full resolution and the deficit of one patient stayed stable.

The similarity of the results between different series shows the effectiveness of Endoscopic Endonasal Approach in chiasmal decompression. After the resection of craniopharyngiomas, panhypopituitarism and DI are especially common in terms of endocrinopathy.

However, in our study, none of the patients experienced postoperative panhypopituitarism, 4 of the patients had preoperative panhypopituitarism (33.3\%) which improved postoperatively. 6 patients developed postoperative DI, 4 of them had it totally resolved, while only 2 patients (33.3\%) suffered from permanent DI. Our results were relatively similar to those of (Gardner et al., 2008) ${ }^{8}$ where, after surgery, only 2 patients experienced new-onset Panhypopituitarism (16.7\%). Of 12 patients who experienced long-term follow-up, only 1 (8.3\%) endured permanent DI. In the postoperative era, four others developed temporary DI, which showed resolution during the last follow-up without further treatment. In other setting results was different for (Park et al., 2017) study as none of the 29 patients with preoperative panhypopituitarism reported recovery of endocrine function. Moreover, of the 36 patients with normal preoperative anterior pituitary function, 5 (14 \%) experienced partial hypopituitarism and 16 (44\%) experienced panhypopituitarism. Among the 98 patients without preoperative DI, 73 (74\%) had no or transient DI 
and, 25 (25.5\%) have postoperatively developed permanent DI. To add up, the results of Cavallo et al., 2014 and his colleagues found that there was deterioration in $43.8 \%$ of cases that had normal anterior pituitary function, and among cases with preoperative panhypopituitarism, only $8 \%$ improved.

Also, preoperative DI remained unchanged in $100 \%$ of patients and the new start of DI was $48.1 \%$. The statistical difference between our study and the other number of studies might be due to our small sample size and the low incidence of preoperative panhypopituitarism.

However, the incidence of postoperative diabetes insipidus was almost the same and showed to be higher in patients with lesions involving the pituitary stalk (trans-infundibular type 2 lesions) according to (Kassam et al., 2008) ${ }^{9}$ classification for craniopharyngioma. Craniopharyngiomas are very challenging tumors and the optimal modality of treatment remains controversial. The best result in terms of recurrence-free survival has been correlated with intensive surgical therapy. However, complete surgical resection relies on the location of the tumor, size, and anatomical relation with neighboring vital neurovascular structures. In 9 patients (75\%) we obtained Gross Total Resection (GTR) and in 3 patients (25\%) we obtained Subtotal Resection (STR). Also, GTR achieved (75\%) success rate of completely improved patients, while STR achieved only (25\%) success rate of completely improved patients. The extent of total resection was acceptable when compared to other series in literature such as that of (Cavallo et al., 2014) where a higher GTR rate was achieved in supra-diaphragmatic retrochiasmatic lesions (80\%) and pre-chiasmatic lesions group (72.4\%) in comparison with the pre \& retrochiasmatic lesions (39.1\%). Moreover, safe and radical resection of supradiaphragmatic lesions depends heavily on the relation of the tumor to the infundibulum, a fact emphasized by (Gardner et al., 2008) study. Preservation of endocrine function while attaining respectable extent of resection can be achieved in types I (preinfundibular) and III (retroinfundibular) tumor where the stalk can be isolated and potentially retained, while preserving function must be balanced towards recurrence risk in type II (transinfundibular) tumors. As regards the extent of resection, we found a significant statistical difference when our results were compared to a transcranial approach study on 20 patients by (Sun et al., 2017) ${ }^{10}$ where GTR was achieved in 18 patients (90\%) and only 2 patients (10\%) had STR. Yet, no significant statistical relation was found between GTR via transcranial approach and better postoperative endocrinological outcome. On the contrary in the transcranial literature, the incidence of new endocrinopathy varied from $24 \%$ to $66 \%$ for panhypopituitarism and $43 \%$ to $79 \%$ for DI, while in the endonasal sequence it is $18 \%$ to $67 \%$ for panhypopituitarism and $8 \%$ to $48 \%$ for permanent DI. These distinctions can be clarified by better visualization of the infundibulum, pituitary stalk, and superior hypophyseal branches (Sua et al., 2011) ${ }^{11}$.
In our series, the characteristics of the lesions revealed that tumor consistency was mixed (solidcystic) in $41.7 \%$ (5 patients), cystic in $58.3 \%$ (7 patients). Calcifications of variable degree were found in $100 \%$ (12 patients) of cases. However, we didn't find any significant statistical correlation between tumor consistency and extent of resection. Even though in some studies as (Park et al., 2017) or (Cavallo et al., 2014) the extent of resection was slightly higher in purely cystic lesions than in mixed lesions. In our series, CSF leakage in 4 patients (33.3 $\%)$ was the most frequent surgical complication. The most common medical complication showed to be diabetes insipidus in 6 patients $(50 \%)$, disturbed conscious level (DCL) and seizures in 2 patients (16.7\%). We found our results closely compatible with the literature as postoperative CSF leakage was the most frequent complications encountered by many authors e.g. (Yadav et al., 2015) ${ }^{12}$. Primary endoscopic repair (in the same operation) was performed on all patients with CSF leakage. In our trial, none of the patients had a preoperative lumbar drain as elected by our surgeons. Finally, regarding efficacy outcomes, (66.7\%) of patients had complete vision improvement, while (33.3\%) had partial improvement, achieving $66.7 \%$ efficacy of resection operation. Regarding safety outcomes, (16.7\%) had DCL and seizures, (50\%) had DI, while (33.3\%) had CSF rhinorrhea. GTR achieved (75\%) success rate of completely improved patients, while STR achieved only (25\%) success rate of completely improved patients.

\section{CONCLUSION}

To conclude, in terms of surgical result and tumor management, the Endoscopic Endonasal Approach (EEA) is an efficient surgical procedure for the removal of craniopharyngiomas. This small case series tends to promote the use of the endoscopic endonasl approach to have a greater degree of preservation of endocrine function and visual recovery, while obtaining a respectable extent of resections. However, for the precise assessment of the Endoscopic Endonasal approach, the expansion of the series, both in terms of number of patients and follow-up time, is critical.

\section{REFERENCES}

1. Shibata T, Teishiki M, Sakata T, et al. Urgent optic nerve decompression via an endoscopic endonasal transsphenoidal approach for craniopharyngioma in a 12-month-old infant: a case report. Pediatric neurosurgery. 2018, 53.3: 182-7.

2. Ozgural O, Onur G, Dogan I, et al. Single-center surgical experience of the treatment of craniopharyngiomas with emphasis on the operative approach: endoscopic endonasal and open microscopic transcranial approaches. Journal of Craniofacial Surgery. 2018, 29.6: 572-8.

3. O'steen L and Indelicato J. Advances in the management of craniopharyngioma. F1000Research. 2018, 7. 
4. Graffeo S, Perry A, et al. Pediatric craniopharyngiomas: a primer for the skull base surgeon. Journal of neurological surgery. Part B, Skull base, 2018, 79.1: 65.

5. Younus I, Forbes A , Link MJ, et al. Radiation therapy rather than prior surgery reduces extent of resection during endonasal endoscopic reoperation for craniopharyngioma. Acta neurochirurgica. 2018, 160.7: 1425-31.

6. Park H, Kshettry V, Farrell CJ, et al. Clinical outcome after extended endoscopic endonasal resection of craniopharyngiomas: two-institution experience. World neurosurgery. 2017, 103: 46574.

7. Cavallo L, Giorgio F, Cappabianca P, et al. The endoscopic endonasal approach for the management of craniopharyngiomas: a series of 103 patients. Journal of neurosurgery. 2014, 121.1: $100-13$.

8. Gardner P, Kassam A, Snyderman CH, et al Outcomes following endoscopic, expanded endonasal resection of suprasellar craniopharyngiomas: a case series. Journal of neurosurgery. 2008, 109.1: 6-16.

9. Kassam A, Paul A, Snyderman $\mathrm{CH}$, et al. Expanded endonasal approach, a fully endoscopic transnasal approach for the resection of midline suprasellar craniopharyngiomas: a new classification based on the infundibulum. Journal of neurosurgery. 2008, 108.4: 715-28.

10. Sun F, Sun X, Du X, et al. Factors related to endocrine changes and hormone substitution treatment during pre-and post-operation stages in craniopharyngioma. Oncology Letters. 2017, 13.1: $250-2$.

11. Sua C, Devaney K, Snyderman CH, et al. Craniopharyngioma: a pathologic, clinical, and surgical review. Head \& neck. 2012, 34.7: 103644.

12. Yadav Y, Nishtha Y, Vijay P, et al. Endoscopic endonasal trans-sphenoid management of craniopharyngiomas. Asian journal of neurosurgery. 2015, 10.1: 10. 